of acquisition and extinction of a discrete-trial bar-press response reinforced on a FR-5 schedule. Furthermore, these animals seem to be relatively slow to acquire a free-operant discrimination. Davenport has also found that stump-tails perform poorly during repeated reversals of a spatial discrimination, thus supporting the findings for repeated reversals of an object discrimination. On the other hand, they do not appear to be especially slow in extinguishing a discrete-trial bar-pres response reinforced on a CRF schedule, although perhaps they would be if acquisition and extinction were repeatedly alternated as was done when the FR-5 schedule was used.

\title{
Effect of unconditioned stimulus linked subconvulsive current in chicks'
}

\begin{abstract}
THOMAS A. WEAVER and J. GEOFFREY MAGNUS, California Institute of Technology, Pasadena, Calif. 91109
\end{abstract}

An experiment was done to see if amnesia of one-trial passive-avoidance training could be induced in chicks by readministering the unconditioned stimulus $20 \mathrm{~h}$ after training and then giving immediate subconvulsive current. A similar experiment by Schneider and Sherman using rats had given positive results-results that could not be explained by the "consolidation-interruption" hypothesis used as the basis for much memory work. A significant amount of such amnesia was not found in chicks despite the use of a large number of animals. An upper limit of $20 \%$ was established for the magnitude of the effect. These results reconfirm the "consolidation-interruption" hypothesis in the case of chicks.

Many investigators have used electroconvulsive shock (ECS) to produce retrograde amnesia in a variety of animals (Quartermain et al, 1965; McGaugh, 1966; Lee-Teng \& Sherman, 1966). The animals seem unable to remember events that immediately preceded ECS. The percentage of Ss forgetting has been found to decrease with increasing time between the event and ECS. The half-time for this decay has been variously reported from $8 \mathrm{sec}$ (Lee-Teng \& Sherman, 1966) to several minutes (McGaugh, 1966).

The first hypothesis ("consolidation-interruption" hypothesis) drawn from such results was that ECS interrupts the consolidation of long-term memories, with normal consolidation taking place in the order of seconds to minutes. Thus the amount of memory retained by the animal is just the amount that was consolidated before ECS. Recently, however, it has been suggested (Schneider \& Sherman, 1968; Misanin et al, 1968; Robustelli et al, 1968) that the amnesia produced by ECS could be the result of an inhibition of the S's ability to retrieve or act on a consolidated memory. An experiment done by Schneider \& Sherman (1968) seems to support this new interpretation. They trained rats in one trial to passively avoid a footshock (US), and $6 \mathrm{~h}$ later they repeated the footshock and then gave immediate ECS. This resulted in a significant level of amnesia. When the footshock was not given with the ECS, or when the interval between footshock and ECS was increased to $30 \mathrm{sec}$, no amnesia resulted. Their interpretation of this effect is that this treatment puts the animal in an "aroused" state in which immediate ECS can suppress the subsequent performance of the avoidance response. This effect will be referred to as "rearousal amnesia." Its occurrence casts doubt on the "consolidation-interruption" hypothesis which predicts that ECS given under any conditions after the conclusion of the consolidation period (about $30 \mathrm{sec}$ ) should produce no amnesia.

The present experiment was done to check the existence of "rearousal amnesia" in chicks. Subconvulsive current (SCC) was used in place of ECS in this experiment since it has been used most often in memory consolidation work with chicks. Lee-Teng (1969) has shown that SCC just below the convulsive threshold produces retrograde amnesia with the same effectiveness and time dependence as ECS.

\section{METHOD}

The basic experimental setup is that developed by Lee-Teng (Lee-Teng \& Sherman, 1966). Newly hatched white leghorn cockerels (Strain k155) were used in the experiment. Between 10 and 11 a.m. on the morning of their first day, the chicks were briefly anesthetized with halothane, and small electrodes (No. 16 fishhooks) were implanted under the skin just above each ear. The chicks were then placed individually in topless, white cylindrical containers which were kept in the experimental room where the temperature was between 82 and $90 \operatorname{deg} F$ and the humidity between $30 \%$ and $50 \%$. They remained in these cartons throughout the experiment.

Between 3:00 and 4:30 p.m. (of the same day), after the chicks had had a chance to become accustomed to their new environment, they were trained in one trial not to peck at a small metal lure. The lure consisted of a 3-mm metal bead held on a long, stiff wire. This lure was dipped in methyl anthranilate (MeA), a chemical which chicks find distasteful, and then held $1 \mathrm{~cm}$ from each chick's beak for $5 \mathrm{sec}$ (measured from the time it oriented toward it). Ninety per cent of the chicks pecked at the metal lure, most within $2 \mathrm{sec}$. Those that didn't peck were not included in the results. Chicks that did peck would typically shake their heads $2-3 \mathrm{sec}$ later, presumably indicating the time when they tasted the MeA.

The next morning (Day 2) between $11 \mathrm{a} . \mathrm{m}$. and $1 \mathrm{p} . \mathrm{m}$., the chicks were given a similar training on a slightly different lure. This lure had a red plastic bead in place of the metal bead described above. In this training, however, the chicks were given a 12-mA, 0.25-sec, 60-cycle subconvulsive current as soon as they shook their heads. Chicks that did not peck at the red lure (about 30\%) were not included in the results. The red lure was used as a means of readministering the unconditioned stimulus of the first training (i.e., the taste of $\mathrm{MeA}$ ). The metal lure was not used since the chicks had just been trained not to peck at it.

The chicks' retention of their first training was tested between 3 and 4 p.m. of Day 2 ( $24 \mathrm{~h}$ after training) by presenting the metal lure (wet with MeA) for $5 \mathrm{sec}$ and noting whether they pecked at or avoided it.

Besides the experimental group whose treatment has been described above, four control groups were run simultaneously. The groups were mixed randomly together and tested blind. They received identical treatment as the experimental group except where otherwise noted. The chicks in the basic control group (C1) were trained with both lures wet with $\mathrm{MeA}$ as before, but weren't given SCC after the red lure training. Those in a second control group (C2) were "trained" on dry lures but received SCC after the second training. The chicks in the third group (C3) were "trained" on dry lures and not given SCC. Those in the fourth control group (C4) were trained with wet lures but not given SCC until 2 min after the second training. The 2-min delay is much greater than the chick's apparent attention span and memory consolidation time (Lee-Teng \& Sherman, 1966). 
Table 1

Experimental Results

\begin{tabular}{|c|c|c|}
\hline Group & Number & $\begin{array}{c}\% \text { not } \\
\text { pecking in } \\
\text { final test } \\
\end{array}$ \\
\hline $\begin{array}{l}\text { E: } \\
\text { Wet Lure Training } \\
\text { SCC }\end{array}$ & 105 & 51 \\
\hline $\begin{array}{l}\text { C1: } \\
\text { Wet Lure Training } \\
\text { No SCC }\end{array}$ & 113 & 64 \\
\hline $\begin{array}{l}\text { C2: } \\
\text { Dry Lure "Training" } \\
\text { SCC }\end{array}$ & 100 & 1 \\
\hline $\begin{array}{l}\text { C3: } \\
\text { Dry Lure "Training" } \\
\text { No SCC }\end{array}$ & 111 & 2 \\
\hline $\begin{array}{l}\text { C4: } \\
\text { Wet Lure Training } \\
\text { Delayed SCC }\end{array}$ & 68 & 57 \\
\hline
\end{tabular}

\section{RESULTS AND DISCUSSION}

The results of this experiment are summarized in Table 1. The performance of the experimental group (E), as measured by the percentage of chicks not pecking in the final test, does not differ significantly from that of the principal control groups (C4, $\chi^{2}=0.37$, and $\mathrm{C1}, \chi^{2}=2.89$ ). All three groups were trained not to peck at the metal lure, readministered the unconditioned stimulus by red lure training, and then given either immediate, delayed, or no SCC, respectively, after the second training. The Schneider-Sherman "rearousal amnesia," which would have been expected to cause a very significant difference between $E$ and both $\mathrm{Cl}$ and $\mathrm{C} 4$, is not apparent.

Control Group C3 (no training, no SCC) establishes a $98 \%$ base pecking level against which the absolute effects of training and SCC on the other groups can be measured. Control Group $\mathrm{C} 2$ demonstrates that $\mathrm{SCC}$ without training does not decrease the chicks' base pecking level. Thus SCC alone does not seem to lower the chicks' activity level or act as a punishment.

It might be objected that the "unerased" training on the red lure given the basic control groups ( $\mathrm{Cl}$ and $\mathrm{C4}$ ) could be generalized and reinforce the chicks' training not to peck at the metal lure, while the experimental group, in which this training is erased by immediate SCC, would show no such reinforcement. Allowing for any such effect, however, would only decrease the insignificant differences between $\mathrm{E}$ and $\mathrm{C} 1$ and $\mathrm{C} 4$.

The insignificant gap of about $10 \%$ $(p \approx 0.1)$ between the groups that received both training and SCC (E and $\mathrm{C} 4$ ) and the group that received training but no SCC (C1) can be explained in terms of a time-independent adverse effect of SCC on the chicks' general ability to remember. A "gap" of this order has been significantly observed in experiments done by Lee-Teng (Lee-Teng \& Sherman, 1966).

Thus, even though the large number of animals used in this experiment would have allowed the significant determination of differences in memory levels down to about $20 \%(p<0.05)$, no significant amount of amnesia was found. This indicates that the "rearousal amnesia" found by Schneider and Sherman under similar conditions in rats either doesn't occur at all or is very much smaller in chicks. The prediction of the "consolidation-interruption" hypothesis is thus confirmed.

Two other experiments have been done which further verify the absence of "rearousal amnesia" in chicks. One was recently done by Lee-Teng, ${ }^{2}$ in which the conditioned stimulus, instead of the unconditioned stimulus, was re-presented. No amnesia was observed. A preliminary experiment by Magnus, using ECS instead of SCC, also showed no effect.

All available evidence thus indicates that such "rearousal amnesia" does not occur in chicks. The apparent need to modify the "consolidation-interruption" hypothesis and to review the work based on it is therefore eliminated.

\section{REFERENCES}

LEE-TENG, E., \& SHERMAN, S. M. Memory consolidation of one-trial learning in chicks. Proceedings of the National Academy of Science, 1966, 56, 926-931.

LEE-TENG, E. Retrograde amnesia in relation to current intensity and seizure pattern in chicks. Proceedings of the 75th Annual Convention, APA, 1967, 2, 87-88.

LEE-TENG, E. Retrograde amnesia in relation to subconvulsive and convulsive currents in chicks. Journal of Comparative \& Physiological Psychology, 1969, 67, 135-139.

McGAUGH, J. L. Time-dependent processes in memory storage. Science, 1966, 153, 1351-1358.

MISANIN, J. R., MILLER, R. R., \& LEWIS, D. J. Retrograde amnesia produced by ECS after reactivation of a consolidated memory trace. Science, 1968, 160, 554555.

QUARTERMAIN, D., PAOLINO, R. M., \& MILLER, N. E. A brief temporal gradient of retrograde amnesia independent of situational change. Science, 1965, 149, 1116-1118.

ROBUSTELLI, F., GELLER, A., \& JARVIK, M. E. Detention, electroconvulsive shock, and amnesia. Proceedings of the 76th Annual Convention, APA, 1968, 3, 331-332.

SCHNEIDER, A. M., \& SHERMAN, W. Amnesia: $A$ function of the temporal relation of footshock to electroconvulsive shock. Science, $1968,159,219-221$.

\section{NOTES}

1. Supported by United States Public Health Service Grant MH-03372, awarded to R.W. Sperry. J.G. M. by P.H.S. Grant 5-T2-GM-333. We wish to thank Evelyn Lee-Ting for useful advice and discussion about this experiment.

2. E. Lee-Teng. Manuscript in preparation. 